\title{
Efficacy and Safety of Current Drug Therapies for Invasive Aspergillosis
}

\author{
Friederike Traunmüller ${ }^{\mathrm{a}}$ Martin Popovic ${ }^{\mathrm{a}, \mathrm{b}}$ Karl-Heinz Konz ${ }^{\mathrm{d}}$ \\ Freyja-Maria Smolle-Jüttner ${ }^{c}$ Christian Joukhadar ${ }^{\mathrm{a}, \mathrm{e}, \mathrm{f}}$

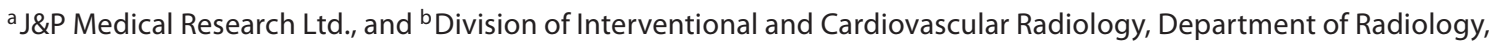 \\ Medical University of Vienna, Vienna, and ' Division of Thoracic and Hyperbaric Surgery, Department of Surgery, \\ Medical University of Graz, Graz, Austria; ${ }^{\mathrm{d}}$ Hospital St. Kamillus der Kliniken Maria Hilf, Mönchengladbach, Germany; \\ e Beth Israel Deaconess Medical Center, and ${ }^{\mathrm{f}}$ Harvard Medical School, Boston, Mass., USA
}

\section{Key Words}

Invasive fungal infections $\cdot$ Molds $\cdot$ Liposomal

amphotericin B · Triazoles $\cdot$ Echinocandins $\cdot$ Haemopoietic

stem cell transplantation $\cdot$ Nephrotoxicity

\begin{abstract}
Invasive aspergillosis $(\mathrm{IA})$ is a potentially lethal infection that affects mostly immunocompromised patients. The therapeutic goals are to restore leucocyte function and to reduce the fungal burden by effective antifungal agents and, contingently, by surgery. Several drugs for the treatment of IA are currently licensed. The longest known among them is amphotericin B (AmB). In well-performed clinical trials, approximately $30-50 \%$ of participants treated with AmB showed complete or partial response. However, this drug is associated with considerable acute and chronic toxicity which was somewhat mitigated by the development of lipid-based formulations. In contrast, voriconazole (VRC) is better tolerated, penetrates well into the central nervous system and may be given intravenously and orally in a sequential manner. The overall rates of favourable response to VRC were similar to that for AmB. Most notably, double-digit rates of complete remission were observed in studies including extraordinarily high proportions of patients with proven IA
\end{abstract}

and specific risk factors. Disadvantages of VRC include the genetically determined interindividual variability of pharmacokinetics and the potential for drug-drug interactions that may require therapeutic drug monitoring. The recently introduced caspofungin (CPF) offers an excellent safety profile, but underperformed in terms of efficacy against mold infections. Other antifungals such as itraconazole and posaconazole are presently recommended as second-line option for the therapy or prophylaxis of (non-)IA. The value of micafungin and anidulafungin remains to be investigated in randomized clinical trials. In guidelines released by relevant medical societies, VRC is recommended as the first choice in the treatment of IA. AmB, preferably given as a liposomal preparation, or combinatory antifungal regimens combining VRC or liposomal AmB with CPF are stated as alternative options.

Copyright $\odot 2011$ S. Karger AG, Basel

\section{Aetiology and Epidemiology of Invasive Aspergillosis}

Invasive aspergillosis (IA) is among the severest complications that affect immunocompromised and critically ill patients [1, 2]. Aspergillus fumigatus is the leading

\section{KARGER}

Fax +41613061234 E-Mail karger@karger.ch www.karger.com (c) 2011 S. Karger AG, Basel

0031-7012/11/0884-0213\$38.00/0

Accessible online at:

www.karger.com/pha
Christian Joukhadar, MD

J\&P Medical Research Ltd.

Auhofstrasse 15/8-9, AT-1130 Vienna (Austria)

Tel. +431876043210

E-Mail christian.joukhadar@jp-medical-research.com 
causative pathogen (approx. 80\% of Aspergillus infections) [3]. Like all members of the Aspergillus species, $A$. fumigatus reproduces asexually through the release of conidia into the air which are inhaled by humans in an unprotected environment, especially in the immediate vicinity of soil or biodegradable waste. The presentation of the fungus in human tissues is usually in the form of individual hyphae or mycelia which are primarily attacked by polymorphonuclear leucocytes [4]. Mycelia may accumulate in pre-existing cavities with a lining of chronic inflammation and fibrosis (aspergilloma). Other histopathological manifestations include necrotizing granulomatous inflammation and infarct-like zones of necrosis with thrombosed vessels due to angio-invasive hyphae [5, 6]. Perivascular infiltration and subsequent angio-infiltration may result in fatal haemorrhage, especially in patients who recover from myelodepression, because the newly formed neutrophils destroy the hyphae invading the vessels [7]. Against this background, it is conceivable that patients with severe and prolonged neutropenia or an inherent dysfunction of granulocytes are particularly predisposed to IA $[8,9]$.

The optimal therapy of IA relies on two cornerstones: first, the restoration of leucocyte counts and immune function, if possible $[10,11]$, and, second, an effective antifungal treatment, which should preferably be initiated at the earliest stage of infection [11-13]. For the latter, several antifungal compounds are currently available. Whichever drug for the treatment of IA in immunocompromised patients is used, complete remission is rarely achieved. Thus, most clinical investigators defined the proportion of patients with either complete or partial resolution of clinical and radiographic signs (widely termed 'favourable response') as the primary end point in their trials. In distinct cases, surgical procedures to reduce the fungus load may complement the antifungal therapy [12, 14].

\section{Amphotericin B}

\section{Efficacy of Amphotericin B and Its Lipid-Based}

\section{Formulations}

Amphotericin B (AmB), a polyene antimycotic agent, has been the mainstay for treating life-threatening, deepseated fungal infections for decades. Its basic mechanism of action is the formation of micellar aggregates with ergosterol, the principal sterol of fungal cell membranes, which leads to an enhanced ion permeability of the membranes and consequently to depolarization and cell death.
AmB's broad antifungal spectrum includes almost all human pathogenic fungi [15]. Due to its insolubility in water at a physiological $\mathrm{pH}, \mathrm{AmB}$ was initially used in association with sodium deoxycholate as an emulsifying agent (D-AmB). A review by Denning of the scientific literature showed that the efficacy of conventional D-AmB given for $\geq 14$ days exhibited response rates that varied highly with the nature of the underlying disease. Renal and heart transplant recipients with pulmonary IA showed average response rates of $83 \%$, while liver transplantation was associated with poorer outcome (20\%). Patients with bone marrow transplantation, haematological malignancies or AIDS responded in 33, 54 and 37\%, respectively. None of the immunocompromised patients with cerebral aspergillosis survived, while non-immunocompromised patients from the same case series had a better prognosis (response rate 33\%) [16].

Lipid-associated formulations, i.e. AmB lipid complex, AmB colloidal dispersion and liposomal AmB (L-AmB), have mainly been developed to circumvent the nephrotoxic potential of AmB. Results from animal experiments were promising in that these preparations might enhance response rates in invasive fungal infections by allowing for the administration of higher doses compared to conventional $\mathrm{D}-\mathrm{AmB}[17,18]$. However, this expectation was not met by the results from pro- and retrospective human studies [19-24].

Among the lipid-based formulations of AmB, L-AmB $\left(\right.$ AmBisome ${ }^{\circledR}$ ) is best studied in randomized, comparative trials on IA $[19,25,26]$. In a trial enrolling 66 neutropenic patients with documented or suspected invasive pulmonary fungal infections (Aspergillus spp. >90\%) and evenly balanced baseline characteristics, either $5 \mathrm{mg} / \mathrm{kg} /$ day of $\mathrm{L}-\mathrm{AmB}$ or $1 \mathrm{mg} / \mathrm{kg} /$ day of $\mathrm{D}-\mathrm{AmB}$ was given. On day 14 , no statistical difference between the two treatment arms in the rates for complete or partial response was found [19].

However, adequate dosing of $\mathrm{L}-\mathrm{AmB}$ is still a matter of debate. Ellis et al. [25] randomly allocated bone marrow transplant recipients with pulmonary IA to a treatment with either 1 or $4 \mathrm{mg} / \mathrm{kg}$ of L-AmB. Neither the clinical response nor the 6-month mortality directly attributable to IA, nor the occurrence of moderate-to-severe adverse events was significantly different in the treatment arms. Interestingly, the number of bone marrow transplant recipients showing complete radiological remission of pulmonary IA at the end of therapy was higher in the group treated with $1 \mathrm{mg} / \mathrm{kg} / \mathrm{day}$ compared to the group treated with $4 \mathrm{mg} / \mathrm{kg} / \mathrm{day}$ (17 vs. $2 \%$; $\mathrm{p}=0.016$ ). On the other hand, the proportion of patients with proven IA was lower in the low-dose group. Generally, the number of cases 
Table 1. Overview of prospective clinical trials on IA that were performed in compliance with the European Organization for Research and Treatment of Cancer/Mycoses Study Group standards as effective in the respective publication year

\begin{tabular}{|c|c|c|c|c|c|c|c|c|c|c|}
\hline Drug & $\begin{array}{l}\text { Publ. } \\
\text { year }\end{array}$ & $\begin{array}{l}\text { Total } \\
\text { daily MD }\end{array}$ & $\begin{array}{l}\text { Eligible } \\
\text { subjects } \\
\mathrm{n}\end{array}$ & $\begin{array}{l}\text { Salvage } \\
\text { therapy } \\
\%\end{array}$ & $\begin{array}{l}\text { Allo- } \\
\text { TX } \\
\%\end{array}$ & $\begin{array}{l}\text { Data } \\
\text { analysis }\end{array}$ & $\begin{array}{l}\text { Diagnosis } \\
\text { proven } \\
\%\end{array}$ & $\begin{array}{l}\text { Remission } \\
\text { complete/partial } \\
\%\end{array}$ & $\begin{array}{l}\text { Mortality } \\
\text { crude/IA- } \\
\text { attributed, \% }\end{array}$ & $\begin{array}{l}\text { Discon- } \\
\text { tin., } \%\end{array}$ \\
\hline D-AmB [27] & 2002 & $1-1.5 \mathrm{mg} / \mathrm{kg}$ & 133 & 0 & 27 & MITT & 31 & $17 / 15(10 \text { days })^{1}$ & $42 / \mathrm{NA}$ & NA \\
\hline $\mathrm{ABCD}[20]$ & 2002 & $6 \mathrm{mg} / \mathrm{kg}$ & 88 & 0 & 49 & ITT & 31 & 6/7 (13 days) & $52 / 40$ & 22 \\
\hline L-AmB [25] & 1998 & $4 \mathrm{mg} / \mathrm{kg}$ & 46 & 0 & 11 & ITT & 26 & $2 / 52^{2}$ (19 days) & $67 / 20^{3}$ & 2 \\
\hline L-AmB [25] & 1998 & $1 \mathrm{mg} / \mathrm{kg}$ & 41 & 0 & 17 & ITT & 20 & $17 / 41^{2}$ (18 days) & $59 / 22^{3}$ & 4 \\
\hline L-AmB [26] & 2007 & $3 \mathrm{mg} / \mathrm{kg}$ & $107^{4}$ & 0 & 16 & MITT & 7 & $50^{5}$ (14 days $)$ & 29/NA & 13 \\
\hline VRC [27] & 2002 & $8 \mathrm{mg} / \mathrm{kg}$ i.v. & 144 & 0 & 32 & MITT & 47 & $21 / 32(77 \text { days })^{1}$ & $29 / \mathrm{NA}$ & 'seldom' \\
\hline VRC $[28]$ & 2002 & $6 \mathrm{mg} / \mathrm{kg}$ i.v. & 116 & 48 & 25 & ITT & 41 & $\begin{array}{l}\text { 14/34 (approx. } 90 \\
\text { days) }\end{array}$ & $38 / \mathrm{NA}^{6}$ & 4 \\
\hline ITC [29] & 2001 & 200 mg i.v. & 31 & 45 & 10 & ITT & 13 & 10/29 (98 days) & 19/NA & 16 \\
\hline PSC [30] & 2007 & 800 mg p.o. & 107 & 100 & 56 & MITT & 100 & 7/36 (56 days) & NA & 'rare' \\
\hline $\mathrm{CPF}[31]^{7}$ & 2009 & $50 \mathrm{mg}$ & 61 & 0 & 0 & MITT & 2 & $2 / 31$ (15 days) & $47 / 30$ & 0 \\
\hline $\mathrm{CPF}[32]^{7}$ & 2010 & $50 \mathrm{mg}$ & 24 & 0 & 100 & MITT & 0 & 0/42 (24 days) & $50 / 21$ & 0 \\
\hline
\end{tabular}

The trials included $74-100 \%$ pulmonary and/or paranasal sinus infections and were comparable in study endpoints. $\mathrm{ABCD}=$ AmB colloidal dispersion; $\mathrm{VRC}=$ voriconazole CPF $=$ caspofungin; publ. year = publication year; $\mathrm{MD}=$ maintenance dose; Allo$\mathrm{TX}=$ proportion of subjects with allogeneic haemopoietic stem cell or solid-organ transplantation; discontin. = discontinuation; (M)ITT = (modified) intention-to-treat analysis; NA = not available; remission $=$ values for evaluable patients at the end of therapy (the median duration of study therapy is given in parentheses); Mortality: assessed at 12 weeks, 'IA-attributed' refers to IA as sole cause of death; discontinuation of therapy for adverse events probably or possibly related to the study drug; i.v. = intravenous administration for at least 7 days, completion of therapy with oral standard doses.

${ }^{1}$ Assessment at 12 weeks. ${ }^{2}$ Radiographic response only. ${ }^{3}$ Mortality at 6 months. ${ }^{4}$ Including $\leq 4$ cases with infections due to $Z y$ gomycetes and Phaeoacremonium spp. ${ }^{5}$ Complete or partial response. ${ }^{6}$ Value for the proportion of patients (52\%) treated with VRC as first-line therapy. ${ }^{7}$ Single study with two strata separately published. of proven Aspergillus infection in this trial (overall 20 out of 87 patients) was too low to draw a firm conclusion regarding a dose-response relationship [25].

In a more recently performed double-blinded, randomized human study ('AmBiLoad'), a standard dose and a high-dose regimen of L-AmB (3 and $10 \mathrm{mg} / \mathrm{kg}$, respectively) were compared in a total study collective of 201 immunocompromised patients with proven or probable IA (pulmonary aspergillosis in approx. 90\%) and neutropenia at baseline. On day 14, the rates of overall favourable response (complete or partial remission) with 50 and $46 \%$ for standard and high dose, respectively, were highly comparable $(\mathrm{p}=0.65)$. The corresponding rates of survival at 12 weeks were 71 and 58\% (not significant). The non-inferiority of the lower dose of L-AmB was irrespective of the presence of prognostic factors associated with poor outcome, i.e. allogeneic haemopoietic stem cell transplantation (HSCT), uncontrolled disease or neutropenia at baseline [26].

An overview of results of well-performed prospective trials with diverse AmB preparations is given in table 1.
In summary, a favourable therapeutic response to lipidbased AmB preparations can be expected in $40-60 \%$ of patients with IA after approximately 3 weeks of therapy. Comparative clinical studies could not demonstrate superior efficacy of lipid-based AmB formulations over D$A m B[19,20]$. Likewise, standard dose regimens of L$\mathrm{AmB}$ were equally effective as high-dose regimens [25, 26]. However, inhomogeneity of study collectives and varying levels of diagnostic certainty of IA may represent a bias to the study results.

\section{Tolerability of $A m B$}

$\mathrm{D}-\mathrm{AmB}$ is well known for frequently causing acute and potentially lethal infusion-related reactions involving symptoms like fever, chills, hypotension, dyspnoea, tachycardia, headache and nausea, which are thought to be triggered by the liberation of inflammatory mediators via stimulation of toll-like receptors and the induction of a CD14-dependent mechanism [33, 34]. Although the concomitant administration of anti-inflammatory drugs may mitigate these symptoms, and the evolution of a cer- 
tain tolerance may be observed later in the course of therapy [34], great effort was laid on the development of better tolerated lipid-associated formulations of AmB. However, among these, only L-Amb showed a significant benefit in the prevention of infusion-related toxicity compared to $\mathrm{D}-\mathrm{AmB}[20,21,35]$.

In addition to infusion-related adverse effects, $\mathrm{AmB}$ may be associated with considerable cumulative toxicity like cardiotoxicity [36, 37], neurotoxicity [38] and, most notably, nephrotoxicity (60-80\% of patients), the latter manifesting in tubular injury and a poorly understood renal vasoconstriction [39]. Although AmB's nephrotoxic effects are to a certain extent preventable (e.g. by sodium supplementation) and reversible [40], they represent the main dose-limiting determinants. Fortunately, all approved lipid-based formulations were shown to significantly reduce the likelihood of severe azotaemia compared to conventional $\mathrm{D}-\mathrm{AmB}$, even in patients treated concomitantly with other nephrotoxic drugs $[19,20,35]$. Thus, in many hospitals, conventional D-AmB, despite its lower cost, is largely abandoned as a therapeutic agent against IA [41]. Despite its unfavourable safety profile, $\mathrm{AmB}$ still represents the best proven and most important therapeutic option in salvage situations and in the management of breakthrough infections.

\section{Voriconazole}

\section{Efficacy of Voriconazole in the Therapy of IA}

Voriconazole (VRC) is a triazole antifungal agent, which demonstrated good activity against Aspergillus strains, even when resistant to $\mathrm{AmB}$ and itraconazole (ITC). As is the case for all triazole antifungal agents, VRC inhibits the fungal enzyme $14 \alpha$-lanosterol demethylase, which catalyses a key step in the membrane synthesis, namely the conversion of lanosterol to ergosterol [42]. VRC can be given both intravenously and orally, allowing for dose flexibility and ambulatory treatment, if clinically reasonable. Factors that render the plasma concentrations of VRC highly unpredictable include genetic polymorphism of the hepatic cytochrome P-450 (CYP) isoenzyme CYP2C19, liver dysfunction, infancy and, in general, the non-linear pharmacokinetics of VRC in adults [43-45]. Several authors, therefore, suggest therapeutic monitoring of drugs metabolized by CYP2C19, as well as VRC itself, as long as VRC therapy is continued $[44,46]$.

Corresponding to its excellent in vitro activity against Aspergillus spp., VRC has shown encouraging clinical ef- ficacy in animal models of IA [47]. Consequently, between 1994 and 1996 Denning et al. [28] conducted an open, non-comparative clinical trial on VRC treatment of histopathologically or microbiologically proven or probable IA. In this study, VRC was given as primary or salvage therapy at intravenous maintenance doses of $3 \mathrm{mg} / \mathrm{kg}$ at 12 -hour intervals for up to 4 weeks. If clinically indicated, treatment was continued orally with $200-$ $300 \mathrm{mg}$ twice daily. In a total of 116 eligible patients with various underlying conditions, the proportion of patients with complete or partial response at their respective end of VRC therapy was $48 \%$. In 2 out of 16 patients showing complete response, relapse occurred at 77 and 112 days, respectively [28].

In a study collective comprising 35 boys and 23 girls with an age range of 9 months to 15 years (median: 7 years), VRC was used within a compassionate use programme [48]. Among these paediatric patients, 42 (72\%) suffered from probable or definite IA, mostly on the basis of haematological disorders or chronic granulomatous disease. Fourteen patients (33\%) underwent bone marrow/stem cell transplantation. A sequential regimen of VRC with intravenous doses of $4(-5) \mathrm{mg} / \mathrm{kg}$ twice daily followed by oral doses of 100-300 mg twice daily was administered. The rate of favourable responses in Aspergillus infections after a total of $\geq 90$ days of VRC therapy was $43 \%$. Complete response was observed in only 1 out of 12 subjects with pulmonary aspergillosis and in none of 6 children with cerebral aspergillosis. However, the crude mortality rate of $41 \%$ in this study (all fungal pathogens) was relatively low compared to $75-100 \%$ found in other paediatric studies [49-51].

A randomized trial published in 2002 aimed at comparing the efficacy and safety of VRC and D-AmB in IA [27]. Patients with a broad range of immunocompromising disorders complicated by proven or probable IA were randomly allocated to receive either VRC ( $4 \mathrm{mg} / \mathrm{kg}$ twice daily) or D-AmB (1-1.5 mg/kg once daily). At the earliest, after 7 days the intravenous VRC therapy could be switched to oral administration of $200 \mathrm{mg}$ twice daily, if clinically reasonable. The eligible modified intention-totreat population consisted of 144 and 133 patients in the $\mathrm{VRC}$ and $\mathrm{D}-\mathrm{AmB}$ groups, respectively. The median duration of therapies was 77 and 10 days for VRC and D-Amb, respectively. Patients not responding or intolerant to the study drugs were given another approved antifungal agent instead (or additionally), but were not excluded from the analysis. A favourable response (complete or partial), as assessed at week 12 by independent investigators, was seen in $53 \%$ of patients in the VRC group and in 
$32 \%$ of patients in the $\mathrm{D}-\mathrm{AmB}$ group. The superiority of VRC therapy was statistically significant and was confirmed in a retrospective stratification of the study collective. Variables assessed include the level of certainty of IA diagnosis (as assessed by independent investigators), the underlying condition, the site of infection and the leucocyte counts. Likewise, the overall survival rate was higher in the VRC group (71\%) as compared to the D$\mathrm{AmB}$ group (58\%; $\mathrm{p}=0.02$ ), even though the VRC group included significantly more cases of proven IA. The authors discussed a possible bias from the longer treatment duration in the VRC group. It was emphasized, however, that for a successful outcome in IA, the treatment in the early course of infection is crucial $[12,13,27]$. A later published analysis of this trial showed that fewer patients in the VRC group had to be given another licensed antifungal therapy compared with patients of the $\mathrm{D}-\mathrm{AmB}$ group (36 vs. $80 \%$ ) [52].

A summary of prospective clinical studies on VRC therapy for IA is presented in table 1 . The rates of complete or partial response in acute IA range from 41 to $53 \%$ after approximately 80-100 days of therapy. Over the course of VRC therapy, the time of intravenous administration seldom exceeded 14 days. Of note, the overall length of therapy was not related to the emergence and severity of adverse events. Discontinuation due to drug intolerability occurred, if only rarely, mainly in the first days of therapy. Distinct studies, however, indicated a direct correlation between low plasma trough concentrations and therapeutic failures $[28,53]$. Therefore, therapeutic drug monitoring, if feasible, seems especially advisable in children and multimorbid patients.

At present, there is no randomized trial directly comparing VRC to a lipid-based formulation of AmB available in the medical literature. However, as mentioned earlier, previous studies were not able to confirm differences in clinical efficacy between conventional D-AmB and currently available lipid-based preparations of AmB. Thus, among others, Herbrecht's well-performed trial demonstrating superiority of VRC over D-AmB with respect to therapeutic success, survival and tolerability in IA provided a firm basis for current treatment recommendations by relevant medical societies $[54,55]$. Due to its good ability to penetrate the cerebrospinal fluid, VRC is also the first choice in cerebral aspergillosis [54].

\section{Adverse Events in VRC Therapy}

Adverse side effects of VRC are usually mild and transient. The most noted are visual disturbances in the form of blurred vision, photophobia or altered colour percep- tion. In clinical studies, these side effects occurred during the first week of therapy, yet rarely led to withdrawal of VRC treatment [45, 47]. An elevation of liver enzymes is reversible with few exceptions reported in patients with pre-existing hepatic dysfunction and poor general health [47]. However, it is difficult to unequivocally attribute elevated liver enzymes to VRC therapy, because most of the critically ill patients receive a variety of comedication and may suffer from dermal manifestations of their underlying disease. Less frequent adverse findings include headaches, hypoglycaemia, hallucinations, 'drunken' feeling, rash, facial erythema, cheilitis and increased photosensitivity $[47,56]$. The latter was made responsible for cutaneous squamous cell carcinomas and melanomas emerging in patients after ultra long-term VRC ingestion $(>12$ months) [57-60]. The occurrence of adverse side effects of VRC has been shown to positively correlate with increasing plasma concentrations $[46,56,61]$. Reports of persistent sequelae remain anecdotal [62].

\section{Other Triazole Agents}

\section{Itraconazole}

ITC is a broad-spectrum antifungal agent and has only been available as oral capsules or oral solution for a long time. However, its bio-availability was determined to be only $30-55 \%$ after a standard breakfast in healthy volunteers [63]. To circumvent this disadvantage, an intravenous formulation of ITC complexed with cyclodextrin was introduced into clinical practice. The major drawback of ITC, however, is the fact that this azole is a potent inhibitor of certain subtypes of the cytochrome P-450 family. In particular CYP3A4 is involved in the metabolism of a large number of drugs that are frequently administered in critically ill patients, i.e. oral anticoagulants, calcium channel blockers, statins, most HIV protease inhibitors, certain antineoplastic agents and immunosuppressants, corticosteroids, opiate analgesics, neuro-active substances and many others. Thus, ITC as well as its metabolites are prone to cause potentially relevant interactions with other CYP3A4 substrates [44].

Evidence of ITC's efficacy in proven IA is scarce. Caillot et al. [29] conducted a study on ITC in pulmonary IA in patients with various immunocompromising conditions. Fourteen (45\%) patients had received unsuccessful empirical antifungal therapy prior to enrolment. With a sequential therapy of $200 \mathrm{mg}$ of ITC intravenously once daily for a median duration of 14 days followed by $200 \mathrm{mg}$ 
orally twice daily for a median duration of 79 days, a favourable therapeutic response (complete or partial) was seen in 15 of 31 (48\%) patients during the last under-treatment assessment. Complete remission was observed in 8 patients (26\%) at study end [29]. In the separately reported subgroup of 21 patients with AmB-refractory aspergillosis, 11 patients showed response to ITC. However, in this trial only 4 patients had a definite diagnosis of IA, but the outcome of these patients was not reported. There was a high incidence of adverse events, but severe adverse events and deaths considered to be study drug related did not occur [64]. Similar results were achieved in 1994 in a collective of 76 patients receiving ITC orally from the start at maintenance doses of 200-300 mg twice daily. Of note, in $84 \%$ of subjects, a definite diagnosis of IA was established according to strict criteria. The overall rate of favourable responses after 12 weeks of ITC treatment was $32 \%$. Complete response was achieved in 5 patients with pulmonary infection. After a median duration of therapy of 46 weeks, the proportions of complete and partial responders rose to 26 and $13 \%$, respectively. It should be emphasized, however, that the study collective included a high proportion of only mildly immunocompromised patients. Relapse of infection following completion of therapy was seen in 4 patients. Notably, oral ITC treatment had to be discontinued in 44 (58\%) subjects (for all reasons including inefficacy or death) [65].

In conclusion, the risk of ITC therapy seems to surpass its benefits in this critically ill patient group. Since the development of the second-generation triazole VRC, ITC has become a subordinate agent in the treatment of IA [66]. However, ITC continues to play a role in antifungal prophylaxis in the early phase after allogeneic HSCT [55, 67] and was recommended in the therapy of allergic bronchopulmonary aspergillosis and allergic Aspergillus sinusitis because of its corticoid-sparing effect in these conditions [55].

\section{Posaconazole}

Posaconazole (PSC) is a recently introduced, highly lipophilic antifungal triazole that is structurally derived from ITC. It exhibits superior in vitro activity against Aspergillus spp. compared to VRC and AmB. Of note, PSC inhibited A. fumigatus isolates resistant to $A m B$, VRC and ITC [68]. At present, the drug is available for oral treatment only.

Although the efficacy of PSC in an animal model of IA caused by $A$. fumigatus was equal to $A m B$ and better than ITC [69], limited data in humans are available at present. In a clinical trial on IA, the efficacy of PSC, giv- en in 107 proven cases at a daily dosage of $200 \mathrm{mg} 4$ times daily (in hospital) or $400 \mathrm{mg}$ twice daily (outpatient), was compared to historical controls treated by conventional antifungal regimens (mainly AmB and/or ITC). The patients in both study groups received their antifungal medication as a salvage treatment. The median duration of therapy was 56 and 22 days in the PSC and the control group, respectively. The efficacy of PSC varied with the site of infection, underlying condition as well as pathogenic species. Pulmonary IA was associated with a lower proportion of responders compared to extrapulmonary IA (39vs. 53\%). PSC performed better in infections caused by $A$. niger and A. flavus compared to control regimens. In contrast, the response rate in A. fumigatus infections was not significantly different from that of control regimens (41 and 35\%, respectively) [30]. Lodge et al. [70] described the case of a 64-year-old man who after bilateral lung transplantation developed an A. fumigatus infection that had spread from the lung to the right ankle and adjacent bones. After surgical revision and unsuccessful treatment for 20 days with AmB lipid complex, the patient recovered completely without further complications with PSC at a dosage of $800 \mathrm{mg} /$ day for a total of 12 months [70].

Despite these encouraging results, the use of PSC for the treatment of IA is curtailed by the fact that an intravenous formulation has not yet been developed. The absorption of PSC from the currently available oral suspension is - even in healthy volunteers - highly variable and quickly saturated. In addition, absorption is greatly influenced by a number of factors with particular relevance to critically ill patients [for a review, see 71]. Thus, at present PSC is a therapeutic option merely in patients refractory or intolerant to more conventional antifungal agents [55, 66]. In addition, it is recommended in the Infectious Diseases Society of America guidelines for antifungal prophylaxis in patients at risk [55].

In table 1 , selected studies on the use of triazole antimycotics in IA are summarized for comparison. Further new triazole agents showing possible advantages with respect to gastro-intestinal absorption and safety are currently under investigation in clinical phase II/III trials (isavuconazole, albaconazole, ravuconazole).

Recently, ITC-resistant strains of A. fumigatus, with elevated minimum inhibitory concentrations for VRC, PSC and ravuconazole, were increasingly detected in clinical and environmental specimens in distinct European countries and China $[72,73]$. There is evidence that azole fungicide agents used in agriculture may be in part responsible for this trend [72]. The primary mechanism 
of triazole resistance in A. fumigates is a mutation of the cyp51A gene encoding $14 \alpha$-demethylase. It is worth mentioning that some Aspergillus species less commonly causative for IA show an intrinsically reduced susceptibility to triazoles (and AmB), e.g. A. lentulus and A. viridinutans [74].

\section{Caspofungin}

\section{Efficacy of Caspofungin in IA}

Caspofungin (CPF) is the first approved member of the class of echinocandins and the only member currently licensed for the therapy of IA. Echinocandins act as non-competitive inhibitors of the UDP-glucose- $\beta(1,3)$ D-glucan- $\beta(3)$-D-glucosyltransferase, commonly referred to as $\beta(1,3)$-glucan synthase. This enzyme is especially important in the cell wall synthesis of yeasts and molds [75]. CPF is active against pathogenic Aspergillus and Candida species. Like all echinocandins, $\mathrm{CPF}$ is a high-molecular-weight lipoprotein and can thus be administered by intravenous infusion only. Due to its protein structure, its ability to penetrate into the cerebrospinal fluid is poor.

In all prospective studies currently available in the literature, $\mathrm{CPF}$ was given at a loading dose of $70 \mathrm{mg}$ on day 1 , followed by once daily maintenance doses of $50 \mathrm{mg}$ for a median of 2-4 weeks. The earliest publications reported the use of CPF in compassionate use programmes. Among 83 adult patients with IA, who were refractory or intolerant to AmB, VRC or ITC, 37 (45\%) responded favourably to $\mathrm{CPF}$ treatment. However, CPF therapy was successful in only 3 out of 21 patients after allogeneic HSCT [76]. A further salvage study was conducted in a small group of children between 3 and 16 years of age (mean, 8 years) with various immunocompromising conditions complicated by IA. Ten children received CPF at $50 \mathrm{mg} / \mathrm{m}^{2}$ of body surface area once daily for 6-87 days (median, 43 days). All Aspergillus species isolated were highly susceptible to CPF. At the individual end of therapy, a favourable outcome was observed in 5 patients including one with cerebral involvement. In addition, CPF was well tolerated in this paediatric population [77]. It is worth mentioning that, in salvage studies, radiographic refractoriness after only 1 week of first-line therapy is frequently accepted as an inclusion criterion $[30,48,76,77]$. However, this practice may skew the interpretation of efficacy data, as, in computer tomography examinations, pulmonary lesions may initially increase in volume despite the effectiveness of the first-line therapy [78].

Drug Therapies of Invasive Aspergillosis
In 2009, CPF was evaluated in an open, multicentric phase II study as a first-line therapy in IA. Sixty-one patients with haematological malignancies and IA on the basis of either antineoplastic chemotherapy or autologous HSCT received CPF for a median of 15 days. Due to the rigorous diagnostic criteria used, there was only 1 patient diagnosed with proven IA at enrolment. Therapeutic success was achieved in 20 patients (33\%), with complete response in only 1 of them. As expected, acute leukaemia and neutropenia at baseline were independent prognostic factors tendentially associated with lower response rates (not significant) [31]. A second patient group of this trial, comprising 24 eligible subjects after allogeneic HSCT, was analysed separately [32]. This special patient population is well known for being at the highest risk to die from IA $[79,80]$. In this subset, none of the patients was diagnosed with microbiologically or histopathologically proven IA. Interestingly, the proportion of responders in patients with acute leukaemia, graft-versus-host disease or neutropenia at enrolment was not significantly different compared to patients not presenting with these conditions. The study was prematurely terminated due to low accrual. Overall, a total of 10 patients (42\%) responded partially to CPF treatment, yet complete remission was not observed (table 1).

In summary, among all echinocandins currently available on the market, $\mathrm{CPF}$ is the most promising compound to be utilized in human IA. In clinical studies employing strict diagnostic criteria for IA, approximately $40 \%$ of patients responded favourably. Based on these results, at the 3rd European Conference on Infections in Leukaemia (2009), CPF for primary therapy of IA was upgraded from evidence CIII to CII [66]. However, the rate of complete remissions in respective studies was low. Consequently, at present CPF is licensed for the secondline therapy of IA and for the empirical therapy of presumed fungal infections in patients with febrile neutropenia.

\section{General Tolerability of CPF}

The greatest advantage of CPF is its excellent tolerability which has been confirmed in clinical trials $[31,32,76$, 77]. Adverse events attributed to CPF in clinical trials were usually mild, unspecific symptoms like headache, fever or gastro-intestinal symptoms. Severe adverse events judged to be drug related were rarely observed in children and adults. The most common laboratory findings include mild-to-moderate elevation of the levels of hepatic transaminases and creatinine and haematological abnormalities [31, 32, 76, 77]. In contrast to azoles, 
CPF shows little effect on the cytochrome P-450 enzyme system and does not interact with p-glycoprotein [81]. Thus, the potential for clinically significant interactions with co-administered drugs is low.

\section{Other Echinocandins}

Micafungin (MCF) was introduced into the market in 2005. In case reports and small series, remarkable therapeutic successes with MCF-containing antifungal combinations in leukaemic patients and HSCT recipients with IA, and with MCF monotherapy in a renal transplant recipient with disseminated aspergillosis were reported [8284]. The only available prospective evaluation of MCF in IA was performed by Denning et al. [85]. MCF monotherapy was given either as primary $(\mathrm{n}=12)$ or as salvage therapy $(\mathrm{n}=22)$. The study protocol specified a baseline dose of $75 \mathrm{mg} /$ day and, after at least 7 days, a dose escalation of 75 -mg increments up to a maximum of $225 \mathrm{mg}$, if clinically reasonable. The mean duration of MCF administration was 54 days (7-284). In this study, a complete or partial success was seen in 15 of 34 (44\%) subjects receiving MCF monotherapy. Complete remission was achieved in 3 out of 22 patients (14\%) receiving MCF as salvage therapy.

A further echinocandin, anidulafungin, showed suboptimal efficacy in animal models of pulmonary and disseminated IA. Although the survival of leukopenic rabbits experimentally infected with A. fumigatus was prolonged, and antigenaemia was reduced, anidulafungin at all doses tested was not able to eliminate viable hyphae from tissues [86]. The role of anidulafungin in antifungal combination therapy of difficult-to-treat Aspergillus infections remains to be determined [87].

To date, well-performed randomized trials on the efficacy of MCF or anidulafungin in the treatment of proven or probable IA in humans are lacking in the medical literature. Thus, their current approval is restricted to the treatment of invasive Candida infections.

\section{Antifungal Combination Therapy}

Many investigators have attempted to use antifungal combination therapies to benefit from synergistic or additive effects. However, although numerous in vitro studies and animal models suggest the possibility that this approach might improve the prognosis of IA (reviewed by Steinbach [88]), to date there is no widely accepted strategy.
The most promising combination appeared to be VRC plus CPF. This combination was used in the primary therapy against IA in a prospective, multicenter trial enrolling 40 solid-organ transplant recipients. A historical cohort of 47 patients who had received a lipid-based AmB formulation served as the control. The rates of favourable outcome were 70 and $51 \%$, with the combination regimen and the $\mathrm{AmB}$ monotherapy, respectively. However, this difference did not reach statistical significance $(p=0.08)$ [89]. Encouraging response rates were found retrospectively by use of the combination of CPF and posaconazole in HSCT recipients who developed suspected or proven IA under ITC prophylaxis and failed to respond to CPF monotherapy [90]. CPF may also be combined with lipidbased formulations of AmB. However, in a retrospective study including high proportions of subjects with allogeneic HSCT and graft-versus-host disease, the combination of high-dose L-AmB with CPF offered no advantage over either antifungal agent alone [91]. The combinations of triazoles and $\mathrm{AmB}$ are considered less advantageous because, first, an antagonistic effect may arise from the fact that the inhibition of ergosterol synthesis by azoles deprives $\mathrm{AmB}$ of its target substrate and, second, the results of respective animal studies do not support such combinations [88].

In general, the benefit of combinatory antifungal medication against IA has not been substantiated by large randomized comparative trials. Several agents used in various combinations have not demonstrated clear superiority over monotherapy [88]. Thus, routine administration of a combinatory first-line therapy in IA is not endorsed by experts but may be considered in salvage situations $[54,55,66]$.

\section{Factors Influencing the Comparability of Clinical Trials on IA}

The baseline characteristics and underlying conditions of subjects with IA may considerably vary among studies. These variables, however, are key contributors to the therapeutic success and mortality in IA. For instance, it is well known that IA, on the basis of prolonged neutropenia, allogeneic HSCT or solid-organ transplantation as well as disseminated infection, is associated with the worst prognosis $[79,80]$. Other pivotal variables include the site of infection and whether the study drug is administered as first- or as second-line therapy. Therefore, a stratification of the study population for these risk factors enhances the quality of the study. The most crucial ques- 
tion, however, is that of the certainty of diagnosis and how the diagnosis was made. As the diagnosis of invasive fungal infection is especially fraught with uncertainty, the Invasive Fungal Infections Cooperative Group of the European Organization for Research and Treatment of Cancer and the Mycoses Study Group of the National Institute of Allergy and Infectious Diseases convened a committee of members with the aim to develop diagnostic criteria and definitions to be used for clinical researchers [92]. The primary study end points should also be well defined. Ideally, the grading of response should be made by independent experts on the basis of predefined criteria similar to that for diagnostics [93]. Whichever primary study end point is chosen, most members of the European Organization for Research and Treatment of Cancer/Mycoses Study Group panel agree that the time of assessment should not be before 6 weeks after start of therapy. Lastly, the intention-to-treat analysis is preferable because it fully retains randomization and avoids the erroneous detection of a therapeutic benefit that may arise from exclusion of early drop-outs.

In table 1, only clinical trials performed in compliance with the quality standards stated above are itemized for comparison.

\section{Conclusions}

Several antifungal agents tested in the treatment of IA are currently available. The long-known substance AmB exerts considerable toxicity, notably nephrotoxicity, which is thought to enhance the overall mortality rates in respective clinical studies. If renal function is not an issue, lipid-based $\mathrm{AmB}$ preparations, preferably L-AmB, are considered valuable options, especially for salvage therapy. The compound with the best benefit-to-risk profile appears to be VRC. Thus, this triazole is recommended as the first choice in all guidelines released by relevant medical societies. PSC may be considered in salvage situations. CPF and other echinocandins exhibited promising in vitro efficacy against Aspergillus spp., but could so far not live up to these expectations in human clinical trials.

There is broad consensus that the medicinal therapy of IA should be continued until the clinical manifestations have completely resolved and, apart from scarring, the radiographic signs have disappeared. A temporary increase in the volume of pulmonary lesions during the first week of therapy should not be misinterpreted as a treatment failure.

\section{Acknowledgement}

The present article was supported by an unrestricted grant by Pfizer Corporation.

\section{Disclosure Statement}

J\&P Medical Research Ltd. is an international independent life science research institute basically operating according to the public-private-partnership concept. Christian Joukhadar is chief executive officer of J\&P Medical Research Ltd., owns 100\% options, and is also a consultant for pharmaceutical companies including Pfizer Corporation, the manufacturer of VRC. Friederike Traunmüller is employee of J\&P Medical Research Ltd. All other authors declare having no relationship with companies that make products relevant to the paper and have no conflicts of interest with the present work.

\section{References}

1 Neofytos D, Horn D, Anaissie E, Steinbach W, Olyaei A, Fishman J, Pfaller M, Chang C, Webster K, Marr K: Epidemiology and outcome of invasive fungal infection in adult haematopoietic stem cell transplant recipients: analysis of multicenter prospective antifungal therapy (PATH) Alliance Registry. Clin Infect Dis 2009;48:265-273.

$\checkmark 2$ Lortholary O, Charlemagne A, Bastides F, Chevalier P, Datry A, Gonzalves M, Michel G, Tilleul P, Veber B, Herbrecht R: A multicentre pharmacoepidemiological study of therapeutic practices in invasive fungal infections in France during 1998-1999. J Antimicrob Chemother 2004;54:456-464.
Krishnan S, Manavathu EK, Chandrasekar $\mathrm{PH}$ : Aspergillus flavus: an emerging non- $f u-$ migatus Aspergillus species of significance. Mycoses 2009;52:206-222.

-4 Bonnett CR, Cornish EJ, Harmsen AG, Burritt JB: Early neutrophil recruitment and aggregation in the murine lung inhibit germination of Aspergillus fumigatus conidia. Infect Immun 2006;74:6528-6539.

5 Yousem SA: The histological spectrum of chronic necrotizing forms of pulmonary aspergillosis. Hum Pathol 1997;28:650-656.
-6 Almutairi BM, Nguyen TB, Jansen GH, Asseri AH: Invasive aspergillosis of the brain: radiologic-pathologic correlation. Radiographics 2009;29:375-379.

7 Gorelik O, Cohen N, Shpirer I, AlmozninoSarafian D, Alon I, Koopfer M, Yona R, Modai D: Fatal haemoptysis induced by invasive pulmonary aspergillosis in patients with acute leukaemia during bone marrow and clinical remission: report of two cases and review of the literature. J Infect 2000;41: 277-282. 
8 Gallien S, Fournier S, Porcher R, Bottero J, Ribaud P, Sulahian A, Socié G, Molina JM: Therapeutic outcome and prognostic factors of invasive aspergillosis in an infectious disease department: a review of 34 cases. Infection 2008;36:533-538.

-9 Baddley JW, Marr KA, David RA, Walsh TJ, Kauffman CA, Kontoyiannis DP, Ito JI, Arunmozhi Balajee S, Pappas PG, Moser SA: Patterns of susceptibility of Aspergillus isolates recovered from patients enrolled in the Transplant-Associated Infection Surveillance Network. J Clin Micobiol 2009;47: 3271-3275.

10 Denning DW, Stevens DA: Antifungal and surgical treatment of invasive aspergillosis: review of 2,121 published cases. Rev Infect Dis 1990;12:1147-1201.

-11 Cakir FB, Cakir E, Berrak SG, Uyan ZS, Canpolat C, Karakoc F, Dagli E: Invasive respiratory aspergillosis is a treatable disease with early diagnosis and aggressive therapy. Pediatr Hematol Oncol 2010;27:422-434.

-12 Ali R, Ozkalemkas F, Ozcelik T, Ozkocaman V, Ozkan A, Bayram S, Ener B, Ursavas A, Oza G, Tunali A: Invasive pulmonary aspergillosis: role of early diagnosis and surgical treatment in patients with acute leukemia. Ann Clin Microbiol Antimicrob 2006;27:17.

-13 Vehreschild JJ, Rüping MJ, Steinbach A, Cornely OA: Diagnosis and treatment of fungal infections in allogeneic stem cell and solid organ transplant recipients. Expert Opin Pharmacother 2010;11:95-113.

-14 Khan MA, Dar AM, Kawoosa NU, Ahangar AG, Lone GN, Bashir G, Bhat MA, Singh S: Clinical profile and surgical outcome for pulmonary aspergilloma: nine year retrospective observational study in a tertiary care hospital. Int J Surg 2011;9:267-271.

15 Gallis HA, Drew RH, Pickard WW: Amphotericin B: 30 years of clinical experience. Rev Infect Dis 1990;12:308-329.

16 Denning DW: Therapeutic outcome in invasive aspergillosis. Clin Infect Dis 1996;23: 608-615.

17 Mouton JW, te Dorsthorst DT, Meis JF, Verweij PE: Dose-response relationships of three amphotericin B formulations in a non-neutropenic murine model of invasive aspergillosis. Med Mycol 2009;47:802-807.

- 18 Olson JA, Adler-Moore JP, Julie Schwartz J, Jensen GM, Proffitt RT: Comparative efficacies, toxicities, and tissue concentrations of amphotericin B lipid formulations in a murine pulmonary aspergillosis model. Antimicrob Agents Chemother 2006;50:21222131.

19 Leenders ACAP, Daenen S, Jansen RL, Hop WCJ, Lowenberg B, Wijermans PW, Cornelissen J, Herbrecht R, Van der Lelie H, Hogsteden HC, Verbrugh HA, De Marie S: Liposomal amphotericin B compared with amphotericin B deoxycholate in the treatment of documented and suspected neutropeniaassociated invasive fungal infections. Br J Haematol 1998;103:205-212.
20 Bowden R, Chandrasekar P, White MH, Xin X , Pietrelli L, Gurwith M, van Burik J, Laverdiere M, Safrin S, Wingard JR: A double-blind, randomized, controlled trial of amphotericin B colloidal dispersion versus amphotericin B for treatment of invasive aspergillosis in immunocompromised patients. Clin Infect Dis 2002;35:359-366.

21 Walsh TJ, Hiemez J, Seibel NL, Perfect JR, Horwith G, Lee L, Silber JL, Di Nubile MJ, Reboli A, Bow E, Lister J, Anaissie EJ: Amphotericin B lipid complex for invasive fungal infections: analysis of safety and efficacy in 556 cases. Clin Infect Dis 1998;26:13831396.

22 Denning DW, Marinus A, Cohen J, Spence D, Herbecht R, Pagano L, Kibbler C, Kcmery V, Offner F, Cordonnier C, Jehn U, Ellis M, Collette L, Sylvester R, the EORTC Invasive Fungal Infections Cooperative Group. An EORTC multicenter prospective survey of invasive aspergillosis in haematological patients: diagnosis and therapeutic outcome. J Infect 1998;37:173-180.

23 Wingard JR: Efficacy of amphotericin B lipid complex injection (ABLC) in bone marrow transplant recipients with life-threatening systemic mycoses. Bone Marrow Transplant 1997; 19:343-347.

24 Ringdén O, Marnier F, To Demar J, Rkof P, Tura S, Kuse E, Viviani MA, Gorin NC, Klastersky J, Fenaux P, Prentice HG, Ksionski G: Efficacy of amphotericin B encapsulated in liposomes (AmBisome) in the treatment of invasive fungal infections in immunocompromised patients. J Antimicrob Chemother 1991;28(suppl B):73-82.

25 Ellis M, Spence D, de Pauw B, Meunier F, Marinus A, Collette L, Sylvester R, Meis J, Boogaerts M, Selleslag D, Krcmery V, von Sinner W, MacDonald P, Doyen C, Vandercam B: An EORTC international multicenter randomized trial (EORTC Number 19923) comparing two dosages of liposomal amphotericin B for treatment of invasive aspergillosis. Clin Infect Dis 1998;27:1406-1412.

26 Cornely OA, Maertens J, Bresnik M, Ebrahimi R, Ullmann AJ, Bouza E, Heussel CP, Lortholary O, Rieger C, Boehme A, Aoun M, Horst HA , Thiebaut A, Ruhnke M, Reichert D, Vianelli N, Krause SW, Olavarria E, Herbrecht R, AmBiLoad Trial Study Group: Liposomal amphotericin B as initial therapy for invasive mold infection: a randomized trial comparing a high-loading dose regimen with standard dosing ( $\mathrm{AmBi}$ Load Trial). Clin Infect Dis 2007;44:12891297.

-27 Herbrecht R, Denning DW, Patterson TF, Bennett JE, Green RE, Oestmann J, Kern WV, Marr KA, Ribaud P, Lortholary O, Sylvester R, Rubin RH, Wingard JR, Stark P, Durand C, Caillot D, Thiel E, Chandrasekar PH, Hodges MR, Schlamm HT, Troke PF, de Pauw P, Invasive Fungal Infections Group of the European Organisation for Research and Treatment of Cancer and the Global Asper- gillus Study Group: Voriconazole versus amphotericin B for primary therapy of invasive aspergillosis. N Engl J Med 2002;347:408415.

28 Denning DW, Ribaud P, Milpied N, Caillot D, Herbrecht R, Thiel E, Haas A, Ruhnke M, Lode $\mathrm{H}$ : Efficacy and safety of voriconazole in the treatment of acute invasive aspergillosis. Clin Infect Dis 2002;34:563-571.

29 Caillot D, Bassaris H, McGeer A, Arthur C, Prentice HG, Seifert W, De Beule K: Intravenous itraconazole followed by oral itraconazole in the treatment of invasive pulmonary aspergillosis in patients with hematologic malignancies, chronic granulomatous disease, or AIDS. Clin Infect Dis 2001;33:e83e90.

30 Walsh TJ, Raad I, Patterson TF, Chandrasekar P, Donowitz GR, Graybill R, Greene RE, Hachem R, Hadley S, Herbrecht R, Langston A, Louie A, Ribaud P, Segal BH, Stevens DA, van BurikJH, White CS, Corcoran G, Gogate J, Krishna G, Pedicone L, Hardalo C, Perfect JR: Treatment of invasive aspergillosis with posaconazole in patients who are refractory to or intolerant of conventional therapy: an externally controlled trial. Clin Infect Dis 2007;44:2-12.

-31 Viscoli C, Herbrecht R, Akan H, Baila L, Sonet A, Gallamini A, Giagounidis A, Marchetti O, Martino R, Meert L, Paesmans M, Ameye L, Shivaprakash M, Ullmann AJ, Maertens J, Infectious Disease Group of the EORTC: An EORTC phase II study of caspofungin as first-line therapy of invasive aspergillosis in haematological patients. J Antimicrob Chemother 2009;64:1274-1281.

>32 Herbrecht R, Maertens J, Baila L, Aoun M, Heinz W, Martino R, Schwartz S, Ullmann AJ, Meert L, Paesmans M, Marchetti O, Akan H, Ameye L, Shivaprakash M, Viscoli C, Infectious Diseases Group of the EORTC: Caspofungin first-line therapy for invasive aspergillosis in allogeneic hematopoietic stem cell transplant patients: an European Organisation for Research and Treatment of Cancer study. Bone Marrow Transplant 2010;45:1227-1233

33 Sau K, Mambula SS, Latz E, et al: The antifungal drug amphotericin B promotes inflammatory cytokine release by a toll-like receptor- and CD14-dependent mechanism. J Biol Chem 2003;278:37561-37568.

34 Goodwin SD, Cleary JD, Walawander CA, Taylor JW, Grasela TH: Pretreatment regimens for adverse events related to infusion of amphotericin B. Clin Infect Dis 1995;20: 755-761.

35 Walsh TJ, Finberg RW, Arndt C, Hiemenz J, Schwartz C, Bodensteiner D, Pappas P, Seibel NL, Greenberg RN, Dummer S, Schuster M, Holcenberg JS, National Institute of Allergy and Infectious Diseases Mycosis Study Group: Liposomal amphotericin B for empirical therapy in patients with persistent fever and neutropenia. N Engl J Med 1999;340: 764-771. 
\$6 Googe JH, Walterspiel JN: Arrhythmia caused by amphotericin B in a neonate. Pediatr Infect Dis J 1988;7:73.

- 37 Danaher PJ, Cao MK, Anstead GM, Dolan MJ, De Witt CC: Reversible dilated cardiomyopathy related to amphotericin $\mathrm{B}$ therapy. J Antimicrob Chemother 2004;53:115117.

38 Walker RW, Rosenblum MK: Amphotericin B-associated leukoencephalopathy. Neurology 1992;42:2005-2010.

- 39 Fanos V, Cataldi L: Amphotericin B-induced nephrotoxicity: a review. J Chemother 2000; 12:463-470.

-40 Anderson CM: Sodium chloride treatment of amphotericin B nephrotoxicity. West J Med 1995;162:313-317.

41 Kleinberg M: What is the current and future status of conventional amphotericin B? Int J Antimicrob Agents 2006;27S:S12-S16.

-42 Sutton DA, Sanche SE, Revankar SG, Fothergill AW, Rinaldi MG: In vitro amphotericin $\mathrm{B}$ resistance in clinical isolates of Aspergillus terreus, with a head-to-head comparison to voriconazole. J Clin Microbiol 1999;37: 2343-2345.

43 Li-Wan-Po A, Girard T, Farndon P, Cooley C, Lithgow J: Pharmacogenetics of CYP2C19: functional and clinical implications of a new variant CYP2C19*17. Br J Clin Pharmacol 2010;69:222-230.

-44 Brüggemann RJM, Alffenaar JC, Blijlevens NMA, Billaud EM, Kosterink JGW, Verweij PE, Burger DM: Clinical relevance of the pharmacokinetic interactions of azole antifungal drugs with other coadministered agents. Clin Infect Dis 2009;48:1441-1458.

- 45 Walsh TJ, Karlsson MO, Driscoll T, Arguedas AG, Adamson P, Saez-Llorens X, Vora AJ, Arrieta AC, Blumer J, Lutsar I, Milligan P, Wood N: Pharmacokinetics and safety of intravenous voriconazole in children after single- or multiple-dose administration. Antimicrob Agents Chemother 2004;48:21662172.

-46 Pascual A, Calandra T, Bolay S, Buclin T, Bille J, Marchetti O: Voriconazole therapeutic drug monitoring in patients with invasive mycoses improves efficacy and safety outcomes. Clin Infect Dis 2008;46:201-211.

-47 Herbrecht R: Voriconazole: therapeutic review of a new azole antifungal. Expert Rev Anti-Infect Ther 2004;2:485-497.

-48 Walsh TJ, Lutsar I, Driscoll T, Dupont B, Roden M, Gharahmani P, Hodges M, Groll AH, Perfect JR: Voriconazole in the treatment of aspergillosis, scedosporiosis and other invasive fungal infections in children. Pediatr Infect Dis J 2002;21:240-248.

-49 Abbassi S, Shenep JL, Hughes WT, Flynn PM: Aspergillosis in children with cancer: a 34-year experience. Clin Infect Dis 1999;29: 1210-1219.

50 Shetty D, Giri N, Gonzalez CE, Pizzo PA, Walsh TJ: Invasive aspergillosis in human immunodeficiency virus-infected children. Pediatr Infect Dis J 1997;16:216-221.
51 Walmsley S, Devi S, King S, Schneider R, Richardson S, Ford-Jones L: Invasive Aspergillus infections in a pediatric hospital: a tenyear review. Pediatr Infect Dis J 1993;12: 673-682.

52 Patterson TF, Boucher HW, Herbrecht R, Denning DW, Lortholary O, Ribaud P, Rubin RH, Wingard JR, De Pauw B, Schlamm HT, Troke P, Bennett JE, European Organization for Research and Treatment of Cancer (EORTC) Invasive Fungal Infections Group (IFIG) and the Pfizer Global Aspergillus Study Group: Strategy of following voriconazole versus amphotericin B therapy with other licensed antifungal therapy for primary treatment of invasive aspergillosis: impact of other therapies on outcome. Clin Infect Dis 2005;41:1448-1452.

53 Smith J, Safdar N, Knasinski V, Simmons W, Bhavnani SM, Ambrose PG, Andes D: Voriconazole therapeutic drug monitoring. Antimicrob Agents Chemother 2006;50:15701572 .

54 Böhme A, Ruhnke M, Buchheidt D, Karthaus M, Einsele H, Guth S, Heussel G, Heussel C, Junghanss C, Kern WK, Kubin T, Maschmeyer G, Sezer O, Silling G, Südhoff T, Szelenyi H, Ullmann AJ: Treatment of fungal infections in hematology and oncology. Ann Hematol 2003;82(suppl 2):S133S140.

55 Walsh TJ, Anaissie EJ, Denning DW, Herbrecht R, Kontoyiannis DP, Marr KA, Morrison VA, Segal BH, Steinbach WJ, Stevens DA, van Burik J, Wingard JR, Patterson TF: Treatment of aspergillosis: clinical practice guidelines of the Infectious Diseases Society of America. Clin Infect Dis 2008;46:327360.

56 Boyd AE, Modi S, Howard SJ, Moore CB, Keevil BG, Denning DW: Adverse reactions to voriconazole. Clin Infect Dis 2004;39: 1241-1244.

57 McCarthy KL, Playford EG, Looke DF, Whitby M: Severe photosensitivity causing multifocal squamous cell carcinomas secondary to prolonged voriconazole therapy Clin Infect Dis 2007;44:e55-e56.

58 Cowen EW, Nguyen JC, Miller DD, McShane D, Arron ST, Prose NS, Turner ML, Fox LP: Chronic phototoxicity and aggressive squamous cell carcinoma of the skin in children and adults during treatment with voriconazole. J Am Acad Dermatol 2010;62: 31-37.

59 Miller DD, Cowen EW, Nguyen JC, McCalmont TH, Fox LP: Melanoma associated with long-term voriconazole therapy: a new manifestation of chronic photosensitivity Arch Dermatol 2010;146:300-304.

60 Morice C, Acher A, Soufir N, Michel M, Comoz F, Leroy D, Verneuil L: Multifocal aggressive squamous cell carcinomas induced by prolonged voriconazole therapy: a case report. Case Report Med 2010;2010:351084.

61 Howard A, Hoffman J, Sheth A: Clinical application of voriconazole concentrations in the treatment of invasive aspergillosis. Ann Pharmacother 2008;42:1859-1864.

62 Kadikoy H, Barkmeier A, Peck B, Carvounis PE: Persistent photopsia following course of oral voriconazole. J Ocul Pharmacol Ther 2010;26:387-388

63 Barone JA, Moskovitz BL, Guarnieri J, Hassell AE, Colaizzi JL, Bierman RH, Jessen L: Enhanced bioavailability of itraconazole in hydroxypropyl-beta-cyclodextrin solution versus capsules in healthy volunteers. Antimicrob Agents Chemother 1998;42:18621865

64 Caillot D: Intravenous itraconazole followed by oral itraconazole for the treatment of amphotericin-B-refractory invasive pulmonary aspergillosis. Acta Haematol 2003;109:111118.

65 Denning DW, Lee JY, Hostetler JS, Pappas P, Kauffman CA, Dewsnup DH, Galgiani JN, Graybill JR, Sugar AM, Catanzaro A, Gallis H, Perfect JR, Dockery B, Dismukes WE, Stevens DA: NIAID Mycoses Study Group multicenter trial of oral itraconazole therapy for invasive aspergillosis. Am J Med 1994;97: 135-144.

66 Herbrecht R, Flückinger U, Gachot B, et al: Antifungal therapy in leukemia patients. 2009 update of the ECIL-1 and ECIL-2 guidelines. 3rd European Conference on Infections in Leukemia, September 25-26, 2009, Juan-Les-Pins, France. http://www. eortc.be/home/IDG/ECIL/ECIL3_Antifungal_therapy_Update_2009.pdf (accessed July 18, 2011)

67 Sánchez-Ortega I, Patiño B, Arnan M, Peralta T, Parody R, Gudiol C, Encuentra M, Fernández de Sevilla A, Duarte RF: Clinical efficacy and safety of primary antifungal prophylaxis with posaconazole vs itraconazole in allogeneic blood and marrow transplantation. Bone Marrow Transplant 2011; 46:733-739.

68 Pfaller MA, Diekema DJ, Ghannoum MA, Rex JH, Alexander BD, Andes D, Brown SD, Chaturvedi V, Espinel-Ingroff A, Fowler CL, Johnson EM, Knapp CC, Motyl MR, Ostrosky-Zeichner L, Sheehan DJ, Walsh TJ, Clinical and Laboratory Standards Institute Antifungal Testing Subcommittee: Wildtype MIC distribution and epidemiological cutoff values for Aspergillus fumigatus and three triazoles as determined by the Clinical and Laboratory Standards Institute broth microdilution methods. J Clin Microbiol 2009;47:3142-3146.

69 Groll AH, Walsh TJ: Antifungal efficacy and pharmacodynamics of posaconazole in experimental models of invasive fungal infections. Mycoses 2006;49(suppl 1):7-16

70 Lodge BA, Ashley ED, Steele MP, Perfect JR: Aspergillus fumigatus empyema, arthritis, and calcaneal osteomyelitis in a lung transplant patient successfully treated with posaconazole. J Clin Microbiol 2004;42: 1376-1378. 
-71 Zoller E, Valente C, Baker K, Klepser ME: Development, clinical utility, and place in therapy of posaconazole for prevention and treatment of invasive fungal infections. Drug Des Dev Ther 2010;4:299-311.

-72 Verweij PE, Snelders E, Kema GH, Mellado E, Melchers WJ: Azole resistance in Aspergillus fumigatus: a side-effect of environmental fungicide use? Lancet Infect Dis 2009;9:789795.

-73 Lockhart SR, Frade JP, Etienne KA, Pfaller MA, Diekema DJ, Balajee SA: Azole resistance in Aspergillus fumigatus isolates from the ARTEMIS global surveillance is primarily due to the TR/L98H mutation in the cyp51A gene. Antimicrob Agents Chemother 2011;55:4465-4468.

74 Van der Linden JW, Warris A, Verweij PE: Aspergillus species intrinsically resistant to antifungal agents. Med Mycol 2011;49(suppl 1):S82-S89.

75 Douglas CM: Fungal beta(1,3)-D-glucan synthesis. Med Mycol 2001;39(suppl 1):5566.

76 Maertens J, Raad I, Petrikkos G, et al: Efficacy and safety of caspofungin for treatment of invasive aspergillosis in patients refractory to or intolerant of conventional antifungal therapy. Clin Infect Dis 2004;39:1563-1571.

-77 Zaoutis TE, Jafri HS, Huang L, Locatelli F, Barzilai A, Ebell W, Steinbach WJ, Bradley J, Lieberman JM, Hsiao C, Seibel N, Laws H, Gamba M, Petrecz M, Taylor AF, Strohmaier KM, Chow JW, Kartsonis NA, Ngai AL: A prospective, multicenter study of caspofungin for the treatment of documented Candida or Aspergillus infections in pediatric patients. Pediatrics 2009;123:877-884.

$\checkmark 78$ Caillot D, Latrabe V, Thiébaut A, Herbrecht R, De Botton S, Pigneux A, Monchecourt F, Mahi L, Alfandari S, Couaillier JF: Computer tomography in pulmonary invasive aspergillosis in hematological patients with neutropenia: an useful tool for diagnosis and assessment of outcome in clinical trials. Eur J Radiol 2010;74:e172-e175

-79 Nivoix Y, Velten M, Letscher-Bru V, Moghaddam A, Natarajan-Ame S, Fohrer C, Lioure B, Bilger K, Lutun P, Marcellin L, Launoy A, Freys G, Bergerat J, Herbrecht R: Factors associated with overall and attributable mortality in invasive aspergillosis. Clin Infect Dis 2008;47:1176-1184.
80 Garcia-Vidal C, Upton A, Kirby KA, Marr KA: Epidemiology of invasive mold infections in allogeneic stem cell transplant recipients: biological risk factors for infection according to time after transplantation. Clin Infect Dis 2008;47:1041-1050.

81 Wagner C, Graninger W, Presterl E, Joukhadar C: The echinocandins: comparison of their pharmacokinetics, pharmacodynamics and clinical applications. Pharmacology 2006;78:161-177.

82 Aoki T, Miyamoto T, Mori Y, Yoshimoto G, Yamauchi T, Kamezaki K, Takenaka K, Iwasaki H, Harada N, Nagafuji K, Shimono N, Teshima T, Akashi K: Successful allogeneic stem cell transplantation in two patients with acute myelogenous leukaemia and invasive aspergillosis by antifungal combination therapy. Mycoses 2011;54:e255-e259.

83 Yamada R, Horikawa K, Ishihara S, Hoshino K, Kawaguchi T, Iyama K, Mitsuya H, Asou $\mathrm{N}$ : Successful treatment of Aspergillus liver abscesses in a patient with acute monoblastic leukemia using combination antifungal therapy including micafungin as a key drug Int J Hematol 2010;91:711-715.

84 Wadi J, Al-Kawasmeh SI, Kamel MT, AlJayyousi BB: Disseminated invasive aspergillosis successfully treated with micafungin in a renal transplant recipient. Saudi J Kidney Dis Transpl 2010;21:914-918.

85 Denning DW, Marr KA, Lau WM, Facklam DP, Ratanatharathorn V, Becker C, Ullmann AJ, Seibel NL, Flynn PM, van Burik JA, Buell DN, Patterson TF: Micafungin (FK463), alone or in combination with other systemic antifungal agents, for the treatment of acute invasive aspergillosis. J Infect 2006;53:337349.

86 Petraitis V, Petraitiene R, Groll AH, Bell A, Callender DP, Sein T, Schaufele RL, McMillian CL, Bacher J, Walsh TJ: Antifungal efficacy, safety, and single-dose pharmacokinetics of LY303366, a novel echinocandin B, in experimental pulmonary aspergillosis in persistently neutropenic rabbits. Antimicrob Agents Chemother 1998;42:2898-2905.

87 Gadea I, Mensa J: Potential of anidulafungin in combined therapy (in Spanish). Enferm Infecc Microbiol Clin 2008;26(suppl 14):5155

88 Steinbach WJ: Combination antifungal therapy for invasive aspergillosis: utilizing new targeting strategies. Curr Drug Targets Infect Disord 2005;5:203-210.
89 Singh N, Limaye AP, Forrest G, Safdar N, Munoz P, Pursell K, Houston S, Rosso F, Montoya JG, Patton P, del Busto R, Aguado JM, Fisher RA, Klintmalm GB, Miller R, Wagener MM, Lewis RE, Kontoyiannis DP, Husain S: Combination of voriconazole and caspofungin as primary therapy for invasive aspergillosis in solid organ transplant recipients: a prospective, multicenter, observational study. Transplantation 2006;81: 320-326.

90 Lellek H, Waldenmaier D, Dahlke J, Ayuk FA, Wolschke C, Kröger N, Zander AR: Caspofungin plus posaconazole as salvage therapy of invasive fungal infections in immunocompromised patients. Mycoses 2011; 54(suppl 1):39-44.

-91 Mihu CN, Kassis C, Ramos ER, Jiang Y, Hachem RY, Raad II: Does combination of lipid formulation of amphotericin B and echinocandins improve outcome of invasive aspergillosis in hematological malignancy patients? Cancer 2010;116:5290-5296.

-92 De Pauw B, Walsh TJ, Donnelly JP, Stevens DA, Edwards JE, Calandra T, Pappas PG, Maertens J, Lortholary O, Kauffman CA, Denning DW, Patterson TF, Maschmeyer G, Bille J, Dismukes WE, Herbrecht R, Hope WW, Kibbler CC, Kullberg BJ, Marr KA, Munoz P, Odds FC, Perfect JR, Restrepo A, Ruhnke M, Segal BH, Sobel JD, Sorrell TC, Viscoli C, Wingard JR, Zaoutis T, Bennett JE: Revised definitions of invasive fungal disease from the European Organization for Research and Treatment of Cancer/Invasive Fungal Infections Cooperative Group and the National Institute of Allergy and Infectious Diseases Mycoses Study Group (EORTC/MSG) Consensus Group. Clin Infect Dis 2008;46:1813-1821.

93 Segal BH, Herbrecht R, Stevens DA, Ostrosky-Zeichner L, Sobel J, Viscoli C, Walsh TJ, Maertens J, Patterson TF, Perfect JR, Dupont B, Wingard JR, Calandra T, Kauffman CA, Graybill JR, Baden LR, Pappas PG, Bennett JE, Kontoyiannis DP, Cordonnier C, Viviani MA, Bille J, Almyroudis NG, Wheat LJ, Graninger W, Bow EJ, Holland SM, Kullberg B, Dismukes WE, De Pauw BE: Defining responses to therapy and study outcomes in clinical trials of invasive fungal diseases: Mycoses Study Group and European Organization for Research and Treatment of Cancer consensus criteria. Clin Infect Dis 2008; 47:674-683. 